\title{
Predictors of cesarean delivery in pregnant women with gestational diabetes mellitus
}

\section{Preditores de cesariana em gestantes com diabetes mellitus gestacional}

\author{
Carmem Luiza Lucht Gascho ${ }^{1}$ Danieli Mayumi Kimura Leandro ${ }^{1}$ Thiago Ribeiro e Silva ${ }^{2}$ \\ Jean Carl Silva ${ }^{1,3}$
}

${ }^{1}$ Universidade Regional de Joinville - UNIVILLE, Joinville, SC, Brazil

2 Universidade Positivo, Curitiba, Paraná, PR, Brazil

${ }^{3}$ High-Risk Outpatient Clinic at, Maternidade Hospital Darcy Vargas, Brazil

Address for correspondence Jean Carl Silva, Rua Oscar Schneider 205, casa 10, 89203-040, Joinville, SC, Brazil

(e-mail: jeancarlsilva@gmail.com).

Rev Bras Ginecol Obstet 2017;39:60-65.

\begin{abstract}
Keywords

- cesarean section

- gestational diabetes

- risk factors

\section{Resumo}

Palavras-chave

- cesárea

- diabetes gestacional

- fatores de risco

Purpose The aim of this study was to evaluate which risk factors may lead patients with gestational diabetes mellitus to cesarean delivery.

Methods This was a retrospective, descriptive study. The subjects of the study were pregnant women with gestational diabetes mellitus attending a public maternity hospital in the south of Brazil. The primary outcomes assessed were based on maternal and fetal characteristics. The data were correlated using an odds ratio (OR) with a $95 \%$ confidence interval $(95 \% \mathrm{Cl})$, calculated using multinomial logistic regression.

Results A total of 392 patients with gestational diabetes mellitus were analyzed, and $57.4 \%$ of them had cesarean deliveries. Among the maternal characteristics, the mean age of the patients and the pregestational body mass index were greater when a cesarean delivery was performed ( $p=0.029$ and $p<0.01$ respectively). Gestational age at birth, newborn weight, weight class according to gestational age, and Apgar score were not significant. The analysis of the OR showed that the chance of cesarean delivery was 2.25 times $(95 \% \mathrm{Cl}=1.49-2.39)$ greater if the pregnant woman was obese, 4.6 times $(95 \% \mathrm{Cl}=3.017-7.150)$ greater if she was a primigravida, and 5.2 times (95\% $\mathrm{Cl}=2.702-10.003)$ greater if she had a previous cesarean delivery. The other parameters analyzed showed no differences.

Conclusion The factors that led to an increase in the occurrence of cesarean deliveries included history of a prior cesarean section, first pregnancy, and obesity.

Objetivo O objetivo deste trabalho é avaliar quais os fatores de risco que podem levar pacientes com diabetes mellitus gestacional ao parto cesáreo.

Métodos Trata-se de um estudo retrospectivo descritivo. Foram sujeitos do estudo gestantes portadoras de diabetes mellitus gestacional atendidas em uma maternidade pública do Sul do Brasil. Os desfechos primários avaliados foram baseados em características maternas e fetais. Os dados foram relacionados por meio da razão de chance
\end{abstract}

received

June 21, 2016

accepted

December 20, 2016

published online

February 23, 2017
Copyright $(2017$ by Thieme-Revinter

Publicações Ltda, Rio de Janeiro, Brazil
License terms

(c) (i) $\ominus$ (\$) 
(RC) com intervalo de confiança de 95\% (IC95\%), calculado por meio da regressão logística multinominal.

Resultados Foram analisadas 392 pacientes com diabetes mellitus gestacional, das quais $57,4 \%$ tiveram o parto realizado por via cesariana. Dentre as características maternas, a idade média das pacientes e o índice de massa corporal pré-gestacional foram maiores nas ocasiões em que o parto cesáreo foi realizado $(p=0,029$ e $p<0,01$, respectivamente). Idade gestacional do parto, peso do recém-nascido, classe de peso de acordo com a idade gestacional e o Apgar não foram significativos. Analisando a RC, o fato de a gestante: ser obesa resultou em chance de parto cesáreo 2,25 (IC95\% = 1,492,39 ) vezes maior; ser primigesta resultou em chance de parto cesáreo 4,6 (IC95\% = 3,017-7,150) vezes maior; e apresentar história de cesárea prévia resultou em 5,2 (IC95\% = 2,702-10,003) vezes mais chance de ter uma nova cesárea. Os outros parâmetros analisados não apresentaram diferença.

Conclusão Entre os fatores que acarretam aumento da ocorrência de nascimento por via cesariana, encontram-se: história de cesárea anterior, primeira gravidez e obesidade.

\section{Introduction}

Gestational diabetes mellitus (GDM) is one of the most frequent metabolic disorders during pregnancy, with incidence rates ranging from 1.1 to $14.3 \%$ depending on the adopted diagnostic criteria and the study population. ${ }^{1}$ In Brazil, GDM affects $7 \%$ of all pregnancies. ${ }^{2}$ This pathology is associated with several undesirable pregnancy outcomes, including an increased risk of premature rupture of the membranes, preterm birth, fetal macrosomia, and preeclampsia. $^{2}$

Gestational diabetes mellitus by itself is not an indication for cesarean section, and the delivery route in patients with this condition is based on an obstetric decision. Abdominal delivery is generally recommended in the presence of certain factors, including cephalopelvic disproportion, cervix unfavorable for induction, fetal macrosomia, fetal distress, and risk of intrauterine death. ${ }^{3}$

In addition to the factors mentioned above, several others are associated with a higher incidence of cesarean deliveries, including: age above 30 years; occurrence of prior cesarean deliveries; first gestation; cervical dilation of $3 \mathrm{~cm}$ or less at the time of delivery; gestational age below 37 weeks or above 40 weeks; non-cephalic presentation; prior maternal pathology; previous use of oxytocin in the pre-partum; secondary or tertiary maternal education level; number of prenatal consultations greater or equal to 7; labor during daytime; and maternal overweightness or obesity. ${ }^{4-6}$

Even though the cesarean section has no absolute contraindications, this procedure, like any other surgical procedure, is not risk-free. In some occasions, however, the benefits associated with reducing the maternal-fetal morbidity and mortality outweigh the risks associated with performing a cesarean section.,7 Some studies suggest that unplanned (emergency) cesarean sections result in increased maternal morbidity compared with planned cesareans. ${ }^{8}$ Thus, it is important to identify which risk factors may lead to a requirement for cesarean delivery, so that the procedure can be planned in advance, if necessary, to avoid possible complications for both the mother and the fetus.

The objective of this study was to identify the risk factors related to birth by cesarean section in pregnant women with GDM.

\section{Methods}

This was a retrospective and descriptive study including pregnant women with GDM attending a public maternity hospital in the south of Brazil.

The study was conducted according to the Guidelines and Norms Regulating Research Involving Human Beings (Resolution 466/12 of the Brazilian National Health Council). The research project was approved by the Research Ethics Committee at Hospital Regional Hans Dieter Schmidt, under opinion number 198.351 .

The study included pregnant women with GDM according to the diagnostic criteria of the International Association of Diabetes and Pregnancy Study Groups (IADPSG), aged 18 years or over, with a single gestation and without associated conditions. The participants who presented incomplete data in their medical records were excluded.

The pregnant women received guidance on diet and physical activity. In the absence of adequate glycemic control, oral hypoglycemic agents were associated and, in the case of a new failure in glycemic control, insulin therapy was added. The parameters used in the therapeutic decision included glycemic levels, gestational age, body mass index (BMI), and fetal abdominal circumference (FAC).

The primary outcomes evaluated were maternal age, maternal BMI, nulliparity, occurrence of a prior cesarean section, type of treatment used, glycemic levels, and FAC.

The data were statistically analyzed using the Statistical Package for Social Sciences (SPSS, SPSS Inc., Chicago, IL, USA) software, version 21.0. Means and standard deviations were 
calculated for quantitative variables, and absolute and relative frequencies were calculated for qualitative variables. Multinomial logistic regression models were constructed to calculate odds ratios (ORs) in order to examine the influence of the parameters studied on the delivery route. The Student's $t$ test was used to analyze the hypothesis of equality between the mean of the two groups, and the Mann-Whitney nonparametric test was used when the assumption of normality was rejected. The chi-square test or the Fischer's exact test were used to test the homogeneity of the groups in relation to the proportions. We established 95\% confidence intervals (95\% $\mathrm{CI})$, and $p$ values $<0.05$ were considered as significant.

\section{Results}

A total of 392 patients with GDM were analyzed, and none were excluded. Among the maternal characteristics, the mean age of the patients and the pregestational BMI were higher at the time the cesarean section was performed ( $p<0.029$ and $p<0.01$ respectively). There were no significant differences between the groups in regards to the number of pregnancies, gestational age at the initiation of the prenatal care, FAC, mean fasting and postprandial blood glucose values, and the type of treatment. These data are shown in -Table 1.

The gestational age at delivery, the weight of the newborn, the class of weight of the newborn according to the gestational age, and the Apgar score at the first and fifth minutes also did not differ significantly between the groups. The admission to the intensive care unit was the characteristic that came closest to having statistical significance $(p=0.052)$. These data are presented in -Table 2 .

Regarding the BMI, when this parameter was categorized as adequate or indicating overweightness, the chance of cesarean delivery decreased by 0.7 and 0.4 times respectively, whereas obesity increased the chance of this procedure by 2.2 times.

When we analyzed the OR, we found that primigravida women presented a 4.6 times higher chance of cesarean delivery. Similarly, pregnant women with a history of a prior cesarean section had 5.19 times greater chance of requiring a new cesarean delivery.

Treatment with diet or the use of oral hypoglycemic agents and/or insulin, and the FAC did not influence the outcome. All these data are presented in - Table 3 .

\section{Discussion}

Due to increased maternal and fetal complications arising from GDM, it becomes evident that abdominal delivery is a priority choice for many obstetricians, as observed in our study (57.4\%). However, GDM alone is not an indication for cesarean section or for the interruption of the gestation before 38 weeks. In a study published by Moore et $\mathrm{al}^{9}$ comparing cesarean rates in control versus GDM women, the results between both were similar, with rates of $35 \%$ and $69.44 \%$ respectively. The same data was corroborated in the study published by Zanrosso et al, ${ }^{10}$ in which cesarean section was the delivery route adopted in $60.5 \%$ of the women with GDM.

There is no clear policy for interruption of pregnancy in full-term diabetic pregnant women. A Cochrane systematic review published by Boulvain et $\mathrm{al}^{11}$ showed that labor induction at 38 weeks could reduce the incidence of newborns weighing more than $4,000 \mathrm{~g}$, but not the risks of cesarean section or neonatal morbidities. Nevertheless, Culligan et $\mathrm{l}^{12}$ cited that cesarean section should be the preferred delivery route in this population group because it is

Table 1 Maternal and fetal characteristics related to gestational diabetes mellitus

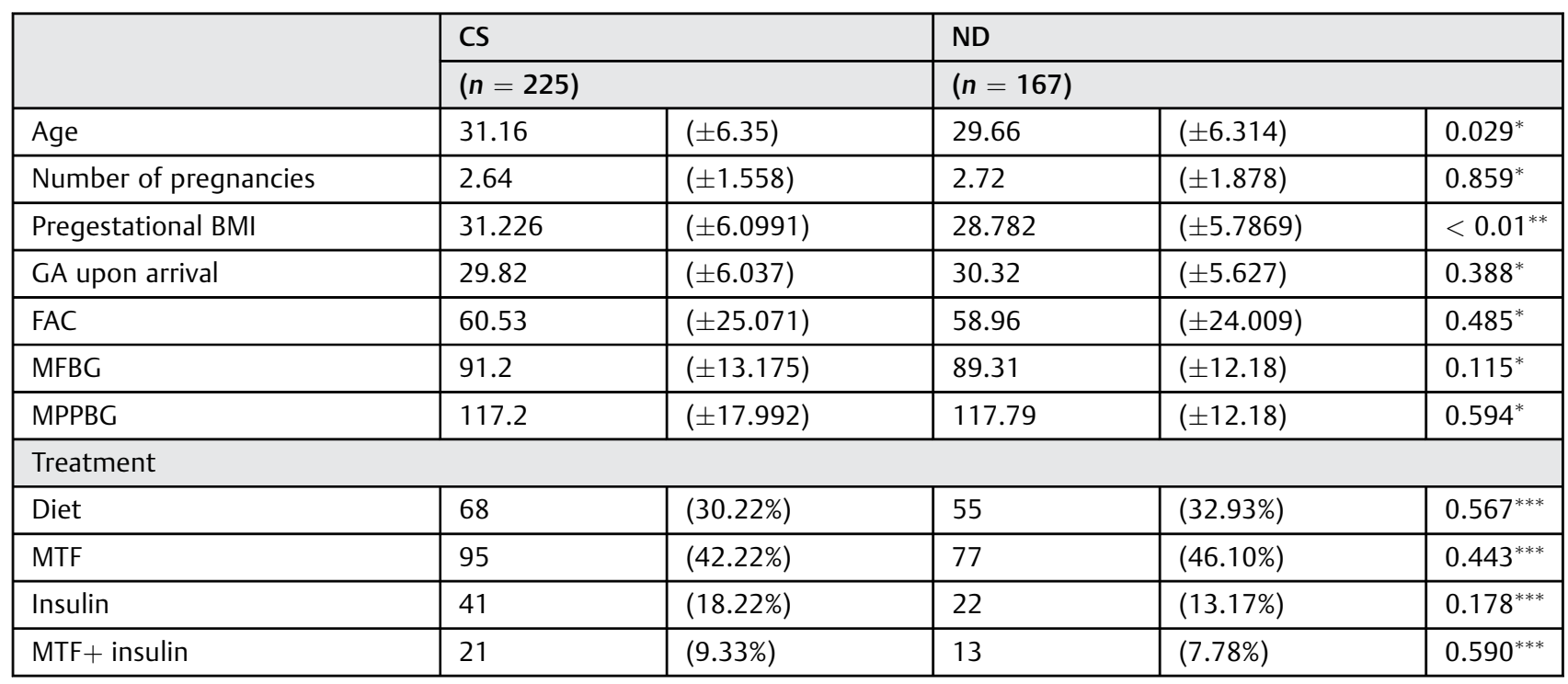

Abbreviations: BMI, body mass index; CS, cesarean section; FAC, fetal abdominal circumference; GA, gestational age; MFBG, mean fasting blood glucose; MPPBG, mean postprandial blood glucose; MTF, metformin; ND, normal delivery.

Notes: *Mann-Whitney test; ${ }^{* *}$ Student's $t$ test; ${ }^{* * *}$ Chi-square test. 
Table 2 Newborns' characteristics related to gestational diabetes mellitus

\begin{tabular}{|c|c|c|c|c|c|}
\hline & \multicolumn{2}{|l|}{ CS } & \multirow{2}{*}{\multicolumn{2}{|c|}{$\begin{array}{l}\text { ND } \\
(n=167)\end{array}$}} & \multirow{3}{*}{$\begin{array}{l}p \\
0.774^{*}\end{array}$} \\
\hline & \multirow{2}{*}{$\begin{array}{l}(n=225) \\
21(\%)\end{array}$} & & & & \\
\hline Prematurity & & & & $14(\%)$ & \\
\hline GA at delivery & $38.60( \pm 1.50)$ & & & $38.52( \pm 1.26)$ & $0.522^{* *}$ \\
\hline NB weight & 3.343 .13 & $( \pm 522.785)$ & 3.280 .84 & $( \pm 460.59)$ & $0.221^{* * *}$ \\
\hline Value by weight clas & & & & & \\
\hline SGA & 20 & $(8.88 \%)$ & 15 & $(8.98 \%)$ & $0.974^{*}$ \\
\hline AGA & 161 & (71.55\%) & 128 & (76.64\%) & $0.257^{*}$ \\
\hline LGA & 44 & (19.55\%) & 24 & (14.37\%) & $0.180^{*}$ \\
\hline Apgar score & & & & & \\
\hline 1st min & 8.01 & $( \pm 0.961)$ & 8.04 & $( \pm 1.219)$ & $0.092^{* *}$ \\
\hline$<7$ on the 1 st $\min$ & 10 & $(4.44 \%)$ & 13 & $(7.78 \%)$ & $0.164^{*}$ \\
\hline 5th min & 8.94 & $( \pm 0.536)$ & 8.94 & $( \pm 0.766)$ & $0.577^{* *}$ \\
\hline$<7$ on the 5 th $\min$ & 2 & $(0.88 \%)$ & 2 & $(1.19 \%)$ & $1.000^{* * * *}$ \\
\hline ICU & 17 & $(7.55 \%)$ & 5 & $(2.99 \%)$ & $0.052^{* * *}$ \\
\hline
\end{tabular}

Abbreviations: 1 st min, first minute; $5^{\text {th }}$ min, fifth minute; AGA, adequate for gestational age; CS, cesarean section; GA, gestational age; ICU, intensive care unit; LGA, large for gestational age; NB, newborn; ND, normal delivery; SGA, small for gestational age.

Notes: *Chi-square test; ${ }^{* *}$ Mann-Whitney; ${ }^{* *}$ Student's $t$ test; ${ }^{* * *}$ Fisher's exact test.

Table 3 Factors associated with cesarean sections

\begin{tabular}{|c|c|c|c|}
\hline & OR & $95 \% \mathrm{Cl}$ & $p$ \\
\hline \multicolumn{4}{|l|}{ Maternal characteristics } \\
\hline Age $\geq 35$ & 1.706 & $0.994-2.927$ & 0.361 \\
\hline Primigravida & 4.645 & $3.017-7.150$ & 0.000 \\
\hline Prior cesarean section & 5.198 & $2.702-10.003$ & 0.000 \\
\hline BMI low weight & 0.213 & $0.190-2.345$ & 0.188 \\
\hline BMI adequate weight & 0.337 & $0.176-0.647$ & 0.024 \\
\hline BMI overweight & 0.563 & $0.326-0.970$ & 0.049 \\
\hline BMI obese & 2.252 & $1.493-3.396$ & 0.000 \\
\hline \multicolumn{4}{|l|}{ Treatment } \\
\hline Diet & 0.767 & $0.274-2.147$ & 0.567 \\
\hline MTF & 0.668 & $0.257-1.734$ & 0.443 \\
\hline Insulin & 1.452 & $0.510-4.137$ & 0.179 \\
\hline MTF + Insulin & 1.219 & $0.592-2.512$ & 0.590 \\
\hline Altered MFBG (> 90) & 1.082 & $0.653-1.795$ & 0.310 \\
\hline Altered MPPBG $(>120)$ & 0.753 & $0.448-1.263$ & 0.536 \\
\hline \multicolumn{4}{|l|}{ FAC 3rd trimester } \\
\hline FAC $p<25$ & 0.891 & $0.333-2.385$ & 0.852 \\
\hline FAC $p$ 25-74 & 0.896 & $0.474-1.694$ & 0.694 \\
\hline FAC $p$ 75-89 & 0.493 & $0.157-1.032$ & 0.139 \\
\hline FAC $p>90$ & 1.513 & $0.920-2.488$ & 0.101 \\
\hline
\end{tabular}

Abbreviations: 95\%Cl, 95\% confidence interval; BMI, body mass index; CS, cesarean section; FAC, fetal abdominal circumference; MFBG, mean fasting blood glucose; MPPBG, mean postprandial blood glucose; MTF, metformin; ND, normal delivery; OR, odds ratio; $p$, Fisher's exact test. 
associated with a reduction in permanent fetal brachial plexus injury and future maternal urinary and anal incontinence. The conclusion is that more studies regarding this are needed.

Births among women older than 35 years of age have been progressively increasing, especially in industrialized countries. According to the Department of Computer Sciences of the Brazilian Unified Healthcare System (DataSUS, in the Portuguese acronym), there was an $18.1 \%$ increase in deliveries by women older than 34 years between 2006 and $2012 .^{13,14}$ The factors that support abdominal delivery in this population group include placenta previa, premature placental abruption, gestational hypertensive disease, GDM, and perinatal mortality, which are the most prevalent conditions in this age group. ${ }^{13,14}$ In our study, we were unable to find a significant relationship between the rate of cesarean sections in women with GDM and the maternal age. Population differences and methodological characteristics may justify the lack of statistical significance in this analysis.

In our study, the fact that a pregnant woman was primigravida and had GDM increased her chance of delivering by cesarean section (adjusted $\mathrm{OR}=4.645,95 \% \mathrm{CI}=3.017$ 7.150). Sakae et $\mathrm{al}^{15}$ in a qualitative study involving 40 primigravidae, showed that women favoring cesarean delivery chose to interrupt the pregnancy with an abdominal delivery due to fear of pain, risks to the binomial motherbaby, and sexual-related problems triggered by normal birth. Such results could be extended to mothers with GDM, in whom the risks of intrapartum complications are higher, increasing even more the fear of normal delivery.

We observe in our study a significant relationship between a prior cesarean section and the choice for surgical delivery in women with GDM (OR $=5.198,95 \% \mathrm{CI}=2.702-10.003)$. Even today, the occurrence of a first cesarean section still determines a new cesarean section in the following pregnancy. Although some evidence shows benefits of vaginal delivery after cesarean section for most women with a previous cesarean section performed with a low transverse uterine incision, the fear of rupture of the uterine scar associated with the risk of fetal macrosomia leads to a surgical interruption of delivery in diabetic pregnant women. ${ }^{16}$

Gonçalves et $\mathrm{al}^{17}$ showed a direct relationship between BMI and cesarean rates, especially in a group with BMI $\geq 30$ $\mathrm{kg} / \mathrm{m}^{2}(p=0.004)$. These data corroborate those found in our study, in which the rates of cesarean delivery were significantly higher in women with GDM, especially when we analyzed those with a BMI of obesity (OR $=2.252,95 \% \mathrm{CI}$ $=1.493-3.396$ ). Thus, it becomes evident that excessive gestational weight is a determining factor for the definition of the delivery route.

A study published by Landon et $\mathrm{al}^{18}$ compared the perinatal outcomes in pregnant women with mild GDM. The results showed a significant reduction in cesarean rates among women with mild GDM treated pharmacologically compared with a control group (13.0\% versus $19.7 \%, p=0.01$ ). It is known that GDM treatment reduces the frequency of fetuses large for gestational age, which may have contributed to the lower rate of cesarean sections. ${ }^{18}$
In our study, the type of treatment was not decisive for the choice of delivery route. Perhaps this difference in results may be linked to methodological issues, since our study lacked a control group for comparisons with other groups managed with pharmacotherapy or diet alone, considering that all pregnant women were treated.

Many perinatal complications in diabetic pregnant women may be reduced with the adequate glycemic control. ${ }^{19}$ On average, $15-25 \%$ of the diabetic mothers give birth to infants with macrosomia ( $>4,000 \mathrm{~g})$, a characteristic that influences the choice for abdominal delivery. ${ }^{15}$ The fetal weight increases with worse maternal glycemic control and greater abundance of nutrients to the fetus. ${ }^{10}$ In our study, we found no significant relationship between mean fasting and postprandial glycemia with increased cesarean rates, but more studies in this regard are still needed.

The measurement of the FAC is a strong indicator of fetal overgrowth and hyperinsulinism, ${ }^{20}$ with values $\geq 75 \%$ for gestational age measured between 29 and 33 weeks being closely related to fetal macrosomia. ${ }^{21}$ In the medical practice, errors in estimating the actual weight by ultrasound exceed $14 \%$, but this test may assist in the decision of the delivery route by identifying fetuses weighing more than 4,250$4,500 \mathrm{~g}$. However, in the present study, FAC in the third trimester showed no significant association with an increased incidence of cesarean delivery. ${ }^{22}$

Due to the retrospective methodological design and the variability of professionals and individualized procedures in the referral center in which the data for this study were collected, we believe that controlled prospective studies may contribute to the credibility of the outcomes found in the present study.

\section{Conclusion}

Our study found a higher incidence of cesarean section than normal delivery in pregnant women with GDM. Among the factors that led to this increased incidence are a history of a prior cesarean section, first pregnancy, and obesity. The other factors evaluated showed no statistical significance, including age over 35 years, type of GDM treatment, fasting blood glucose and postprandial mean blood glucose values, and FAC measured in the third trimester.

\section{References}

1 Detsch JC, Almeida AC, Bortolini LGC, Nascimento DJ, Oliveira Junior FC, Réa RR. Markers of diagnosis and treatment in 924 pregnancies with gestational diabetes mellitus. Arq Bras Endocrinol Metabol 2011;55(06):389-398

2 Brasileira de Diabetes S. Diretrizes da Sociedade Brasileira de Diabetes (2015-2016). São Paulo: A.C. Farmacêutica; 2016

3 Vieira Neta FA, Crisóstomo VL, Castro RCMB, Pessoa SMF, Aragão MMS, Calou CGP. Avaliação do perfil e dos cuidados no pré-natal de mulheres com diabetes mellitus gestacional. Rev Rene. 2014; 15(05):823-831

4 Martino J, Sebert S, Segura MT, et al. Maternal body weight and gestational diabetes differentially influence placental and pregnancy outcomes. J Clin Endocrinol Metab 2016;101(01):59-68 
5 Poobalan AS, Aucott LS, Gurung T, Smith WC, Bhattacharya S. Obesity as an independent risk factor for elective and emergency caesarean delivery in nulliparous women-systematic review and meta-analysis of cohort studies. Obes Rev 2009;10(01):28-35

6 Freitas PF, Sakae TM, Jacomino MEMLP. Medical and non-medical factors associated with cesarean section rates in a university hospital in southern Brazil. Cad Saude Publica 2008;24(05):1051-1061

7 Armson BA. Is planned cesarean childbirth a safe alternative? CMAJ 2007;176(04):475-476

8 Ghahiri A, Khosravi M. Maternal and neonatal morbidity and mortality rate in caesarean section and vaginal delivery. Adv Biomed Res 2015;4:193

9 Moore TR. A comparison of amniotic fluid fetal pulmonary phospholipids in normal and diabetic pregnancy. Am J Obstet Gynecol 2002;186(04):641-650

10 Zanrosso CD, Schuch T, Camassola M, Pizzolotto L, Bisotto C, Andreazza T. Desfechos materno-fetais do diabetes gestacional em serviço terciário de atenção obstétrica. Rev AMRIGS. 2015; 59(02):112-115

11 Boulvain M, Stan C, Irion O. Elective delivery in diabetic pregnant women. Cochrane Database Syst Rev 2001;(02):CD001997

12 Culligan PJ, Myers JA, Goldberg RP, Blackwell L, Gohmann SF, Abell TD. Elective cesarean section to prevent anal incontinence and brachial plexus injuries associated with macrosomia-a decision analysis. Int Urogynecol J Pelvic Floor Dysfunct 2005;16(01): 19-28, discussion 28

13 Teixeira EC, Gurgel HM, Monteiro DLM, Barmpas DBS, Trajano AJB, Rodrigues NCP. Gravidez em mulheres acima de 34 anos no Brasil análise da frequência entre 2006 e 2012. Rev HUPE. 2015;14(01):6-11
14 Silva JL, Surita FG. [Maternal age: perinatal outcomes and mode of delivery]. Rev Bras Ginecol Obstet 2009;31(07):321-325

15 Sakae TM, Freitas PF, d'Orsi E. Factors associated with cesarean section rates in a university hospital. Rev Saude Publica 2009; 43(03):472-480

16 Oliveira TA, Aquino MMA, Mariani Neto C. Indução do parto em pacientes com cesárea anterior. Femina 2009;37(08):427-432

17 Gonçalves CV, Mendoza-Sassi RA, Cesar JA, de Castro NB, Bortolomedi AP. [Body mass index and gestational weight gain as factors predicting complications and pregnancy outcome]. Rev Bras Ginecol Obstet 2012;34(07):304-309 Portuguese.

18 Landon MB, Spong CY, Thom E, et al; Eunice Kennedy Shriver National Institute of Child Health and Human Development Maternal-Fetal Medicine Units Network. A multicenter, randomized trial of treatment for mild gestational diabetes. N Engl J Med 2009;361(14):1339-1348

19 Silva JC, Lopes C, Bertini AM, Lacava B, Soccol H Junior, Ribeiro TE. Impacto do tratamento intensivo do diabetes melito gestacional no peso do recém nascido. ACM Arq Catarin Med. 2010;39(01): 25-29

20 Silva JC, Valle JB, Ferreira BS, Silva MR, Martins L, Silva AL. Parâmetros a serem considerados no tratamento e controle do diabetes gestacional. Femina 2014;42(04):165-169

21 Souza BV, Aita CAM, Silva JC, Bagenstoss R. Marcadores clínicos e bioquímicos de gravidade do diabetes mellitus gestacional. Femina 2012;40(02):117-121

22 Weinert LS, Silveiro SP, Oppermann ML, et al. Gestational diabetes management: a multidisciplinary treatment algorithm. Arq Bras Endocrinol Metabol 2011;55(07):435-445 